\title{
Identification of two novel GATA6 mutations in patients with nonsyndromic conotruncal heart defects
}

\author{
XIKE WANG $^{1,2^{*}}$, WEI JI ${ }^{3 *}$, JIAN WANG $^{3}$, PENGJUN ZHAO ${ }^{3}$, \\ YING GUO $^{3}$, RANG XU ${ }^{1}$, SUN CHEN ${ }^{1}$ and KUN SUN ${ }^{1}$

\begin{abstract}
${ }^{1}$ Children's Heart Center, Xinhua Hospital, Shanghai Jiao Tong University School of Medicine, Shanghai 200092; Shanghai Children's Medical Center, Shanghai Jiao Tong University School of Medicine, Shanghai 200127, P.R. China
\end{abstract} \\ ${ }^{2}$ Department of Pediatrics, Guizhou Provincial People's Hospital, Guiyang, Guizhou 550002; ${ }^{3}$ Department of Cardiology,
}

Received October 30, 2013; Accepted April 10, 2014

DOI: $10.3892 / \mathrm{mmr} .2014 .2247$

\begin{abstract}
GATA binding protein 6 (GATA6) encodes a zinc-finger transcription factor that is essential for normal heart development. Mutations in this gene lead to conotruncal heart defects associated with cyanotic congenital heart disease; however, it remains unclear whether the mutations in GATA6 are also responsible for the development of the nonsyndromic conotruncal heart defects. The coding region exons and flanking intron sequences of GATA6 were screened in 157 patients with nonsyndromic conotruncal heart defects and 300 control subjects. Three heterozygous missense mutations, c.151G $>$ A $(\mathrm{E} 51 \mathrm{~K})$, c.551G $>$ A $(\mathrm{S} 184 \mathrm{~N})$ and c.733G $>\mathrm{C}$ (G245R), were identified in patients with tetralogy of Fallot or persistent truncus arteriosus. The two novel mutations (E51K and G245R) identified in the current study are located in evolutionarily conserved residues of the GATA6 protein. It was demonstrated that these two mutations lead to a significant reduction in the transactivation capacity of downstream genes. The current study presents two novel GATA6 mutations in patients with nonsyndromic conotruncal heart defects and provides novel insights into the pathogenesis of this disease.
\end{abstract}

\section{Introduction}

Cardiac conotruncal defects (CTDs) are cardiac outflow tract defects that occur during the embryonic development of complex congenital heart malformations. Examples of CTDs

Correspondence to: Professor Kun Sun or Dr Sun Chen, Children's Heart Center, Xinhua Hospital, Shanghai Jiao Tong University School of Medicine, 1665 Kongjiang Road, Shanghai 200092, P.R. China

E-mail: sunkun@xinhuamed.com.cn

E-mail: chengsun@hotmail.com

*Contributed equally

Key words: congenital heart disease, genetic mutation, nonsyndromic conotruncal heart defects, transcription factor, GATA6 include: Tetralogy of Fallot (TOF); pulmonary atresia with ventricular septal defect (PA/VSD); double outlet of right ventricle (DORV); transposition of the great arteries (TGA); persistent truncus arteriosus (PTA); and interrupted aortic arch (IAA). CTDs accounted for $25-33 \%$ of all congenital heart defects and $70 \%$ of cyanotic congenital heart disease in 1996 (2). CTDs are the main cause of complex cardiac malformations, mortality and overall serious harm to health in infants, creating a heavy financial burden for families and society $(1,2)$.

Studies have shown that genetic factors are pivotal in the pathogenesis of cardiac CTDs, but the mode of inheritance, the penetrance, and the identities of susceptibility genes are not yet clear $(3,4)$. Previous studies have shown that the 22 q11.2 microdeletion is associated with $75-85 \%$ of cardiac CTDs, but only $6.1-17.9 \%$ of patients with nonsyndromic CTD have 22q11.2 microdeletions $(5,6)$. Therefore, the genetic mechanisms of $>80 \%$ of nonsyndromic cardiac conotruncal malformations are unknown. As a result of this, the screening of disease genes and candidate genes in patients with CTD is a focus of current cardiovascular research. Studies in animal models have demonstrated that the GATA binding protein 6 (GATA6) regulates differentiation and affects the development of CTDs. Homozygous GATA6-knockout mice exhibit developmental endoderm defects that lead to embryonic death $(7,8)$. Studies have demonstrated that conditional inactivation of GATA6 in vascular smooth muscle cells (VSMCs) in mice results in perinatal mortality from a spectrum of cardiovascular defects, including IAA and PTA. Inactivation of GATA6 in the neural crest recapitulates these abnormalities, demonstrating a cell-autonomous requirement for GATA6 in neural crest-derived smooth muscle cells (9). It is therefore necessary to screen for GATA6 mutations in patients with nonsyndromic conotruncal heart defects to enable early disease intervention and genetic counseling.

\section{Materials and methods}

Subjects. The present study was approved by the Medical Ethics Committee of Xinhua Hospital (Shanghai, China). Once informed consent was obtained from the parents of all patients and control subjects, venous blood samples from all participants 
Table I. Primers used to amplify the GATA6 gene.

\begin{tabular}{llll}
\hline Fragment & Forward primer (5'-3') & Reverse primer (5'-3') & Fragment size (bp) \\
\hline 1 & ccgtccectccceaccetctt & gagatcgcgcgcgaggaggaagca & 361 \\
$2-1$ & tggaggcgaggtagcgtgcag & ctcgggtgcgaaggggctcag & 544 \\
$2-2$ & cccgctcgctgctgctcagtt & ccatgggcgggctgggagagt & 591 \\
$2-3$ & cacctgcaggggtcgggcagt & aaacagggeccgagtggagca & 616 \\
3 & ctactggggcgctccgggtgt & agcgggtgggcgttggaacag & 583 \\
4 & tggagaagaaaccagggatga & tgcattcaaattttcacttgag & 590 \\
$5-6$ & cggcggccaaattcttta & aaccataaaaaatgataccgatct & 619 \\
7 & tggccagggtcaggtcagtgg & gagtggcccaagcgcccagtt & 610 \\
\hline
\end{tabular}

GATA6, GATA binding protein 6 .

were collected in an anticoagulant tube with sodium citrate. Karyotype analysis and multiplex ligation-dependent probe amplification were performed in samples from all patients with CTDs. Fluorescence in situ hybridization (FISH) was performed in all patients to identify and exclude patients with genetic deletions such as trisomy 18, trisomy 21 and 22q11.2 deletion. Nonsyndromic patients with CTD were diagnosed by transthoracic echocardiography, computed tomography, cardiac catheterization, and/or surgical inspection. A total of 157 unrelated Chinese patients with nonsyndromic CTD were enrolled in the study from January 2009 to January 2011. Patients included 105 males and 52 females, aged between 1 month and 17 years old with a median age of 3.64 years. CTDs in these patients included: TOF (73 cases); PA/VSD (27); DORV (28); TGA (9); PTA(10); and IAA (10). The present study enrolled 300 healthy unrelated children as healthy controls. All participants were of Han ethnicity. Genomic DNA was isolated from $200 \mu$ blood using a standard phenol-chloroform extraction protocol. The families of the probands (parents and siblings) also underwent physical examination and transthoracic echocardiography, and venous blood samples were analyzed for GATA6 mutations.

Screening for mutations. Seven whole exons and exon-intron boundaries of human GATA6 were amplified. Oligonucleotide primers were designed based on genomic sequences (GenBank accession number NC_000018) using Primer3 software (http://frodo.wi.mit.edu/primer3/) and were synthesized by Shanghai Genesky Bio-Tech (Shanghai, China). Primers were designed so that each exon was flanked by part of the corresponding intron (Table I). For exons 1, 2, 3 and 7, the polymerase chain reaction (PCR) reaction mixture (total, $10 \mu \mathrm{l})$ contained $1.0 \mu \mathrm{l}$ genomic DNA, $1.0 \mu \mathrm{l}$ each primer, $0.2 \mu \mathrm{l}$ dNTP mixture, $5.0 \mu \mathrm{l} 2 \mathrm{X}$ GC buffer I, $2.74 \mu \mathrm{l} \mathrm{ddH}_{2} 0$, and $0.06 \mu 1$ HotTaq DNA polymerase (Takara Biotechnology, Dalian, China). PCR was performed using a GeneAmp 9600 Thermal cycler (Applied Biosystems, Foster City, CA, USA) under the following conditions: Predenaturation at $95^{\circ} \mathrm{C}$ for $2 \mathrm{~min}$, followed by 35 cycles at $96^{\circ} \mathrm{C}$ for $10 \mathrm{sec}$, and annealing and extension at $72^{\circ} \mathrm{C}$ for $4 \mathrm{~min}$. For exons 4 and 5-6, the PCR reaction mixture (total, $10 \mu \mathrm{l}$ ) contained $1.0 \mu \mathrm{l}$ genomic DNA, $1.0 \mu \mathrm{l}$ each primer, $0.2 \mu \mathrm{l}$ dNTP mixture, $1.0 \mu \mathrm{l}$ 2X GC

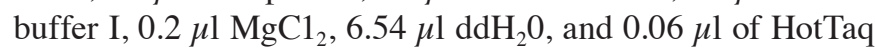
DNA polymerase. PCR cycling conditions were as follows:
11 cycles of predenaturation at $95^{\circ} \mathrm{C}$ for 2 min, denaturation at $96^{\circ} \mathrm{C}$ for $20 \mathrm{sec}$, denaturation at $62^{\circ} \mathrm{C}$ for $40 \mathrm{sec}$, and extension at $72^{\circ} \mathrm{C}$ for $2 \mathrm{~min}$ (annealing temperature was decreased by $0.5^{\circ} \mathrm{C} /$ cycle); 24 cycles of denaturation at $94^{\circ} \mathrm{C}$ for $20 \mathrm{sec}$, annealing at $56^{\circ} \mathrm{C}$ for $30 \mathrm{sec}$ and extension at $72^{\circ} \mathrm{C}$ for $2 \mathrm{~min}$. All PCR products were gel purified using a QIAquick Gel Extraction kit (Qiagen, Hilden, Germany) and then sequenced using the dideoxy chain termination method on an ABI3130XL sequencer (Applied Biosystems). Sequencing results were aligned with the reference sequence using the GenBank BLAST program (http://blast.ncbi.nlm.nih.gov/Blast.cgi). The corresponding sequences of healthy controls were amplified and sequenced as above in order to exclude polymorphisms. GATA6 protein sequences from various species were aligned using ClustalW software (www.clustal.org).

Plasmid construction and cells. The wild-type GATA6 expression plasmid, pcDNA3.1(+)-Homo GATA6 was supplied by Professor Hiroyuki Yamagishi (10). To generate the GATA6 E51K and G245R mutant constructs, mutations were introduced into pcDNA3.1(+)-Homo GATA6 by site-directed mutagenesis-PCR individually. The vector with a luciferase reporter driven by the ANF promoter was a kind gift from Professor Vidu Garg (11). HEK293T cells (Cell Bank of the Chinese Academy of Science, Shanghai, China) were split and seeded into 96 -well plates with 10,000 cells/well in preparation for the following assay.

Transfection and transcriptional assay. Transfection using FuGene HD Transfection reagent (Roche Diagnostics, Mannheim, Germany) was conducted in triplicate as previously described (12), and then the activity of firefly luciferase and LacZ in cell lysates was measured by the Dual-Glo Luciferase Assay system (Promega Corporation, Madison, WI, USA) $24 \mathrm{~h}$ after transfection. HEK239T cells were transfected with $20 \mathrm{ng}$ of wild-type or mutant GATA6, $100 \mathrm{ng}$ reporter construct ANF-luciferase, and $20 \mathrm{ng}$ cytomegalovirus (CMV)-LacZ in each well for correcting the transfection efficiency. Results are presented as the relative luciferase activity, normalized to the co-transfected CMV-LacZ group.

Statistical analysis. Data are presented as the mean \pm standard deviation. The two groups were compared using the $\chi^{2}$ test for 
A

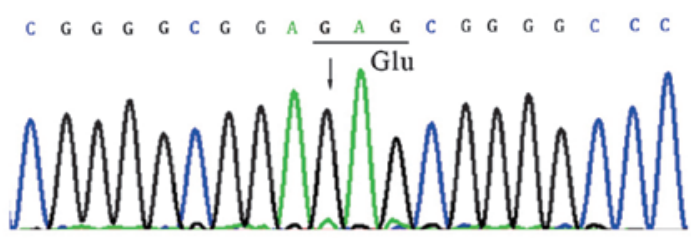

$\mathbf{C}$

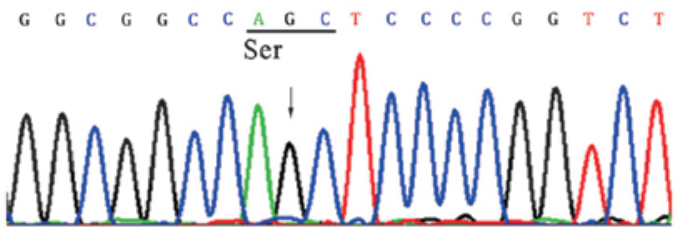

$\mathbf{E}$

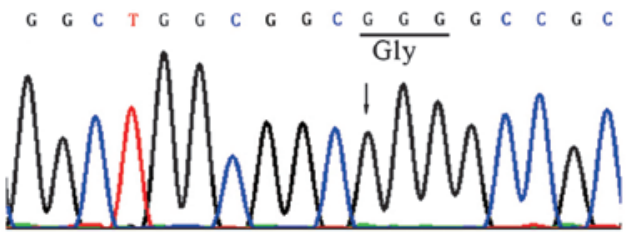

B

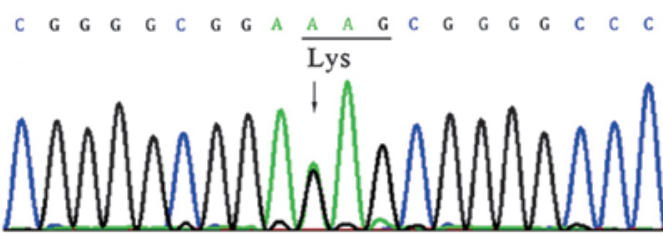

D

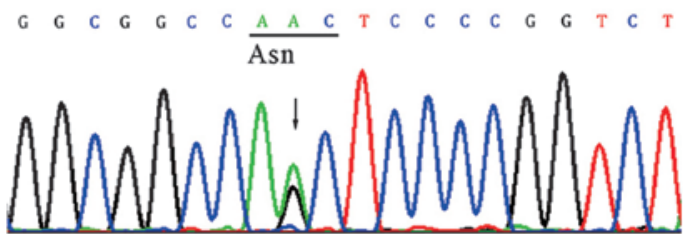

$\mathbf{F}$

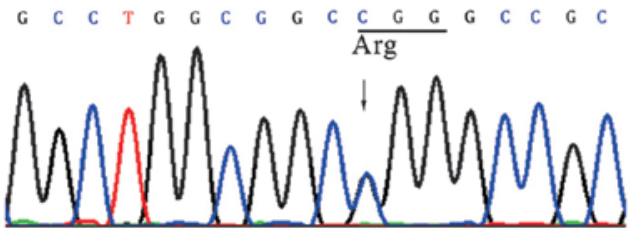

Figure 1. Three heterozygous missense GATA6 mutations were identified in three nonsyndromic conotruncal heart defect patients. (A,C and E) Wild type; (B,D and F) mutant. p.Glu51Lys (E51K), p.Ser184Asn (S184N), p.Gly245Arg (G245R), and their wild-type counterparts are shown. GATA6, GATA binding protein 6.

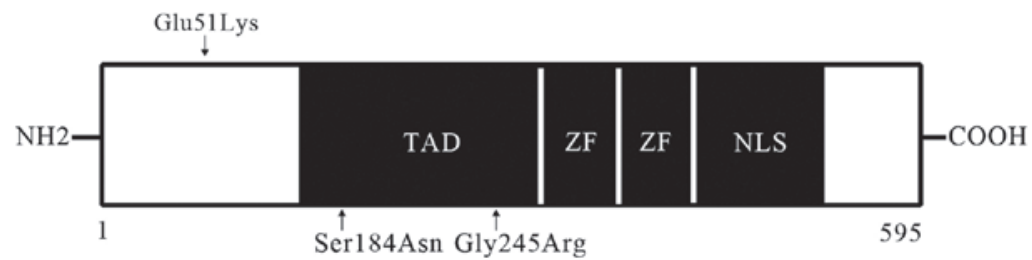

Figure 2. Location of E51K, S184N and G245R in the structural domains of the GATA6 protein. Colored lines represent exons 2-7 encoding amino acids 1-595 of the GATA6 protein. Arrow, location of the mutation; TAD, transcriptional activation domain; ZF, zinc finger domain; NLS, nuclear localization signal; GATA6, GATA binding protein 6.

Homo sapiens
pongo abelii
Bos taurus
Canis lupus familiaris
Sus scrofa
Mus musculus

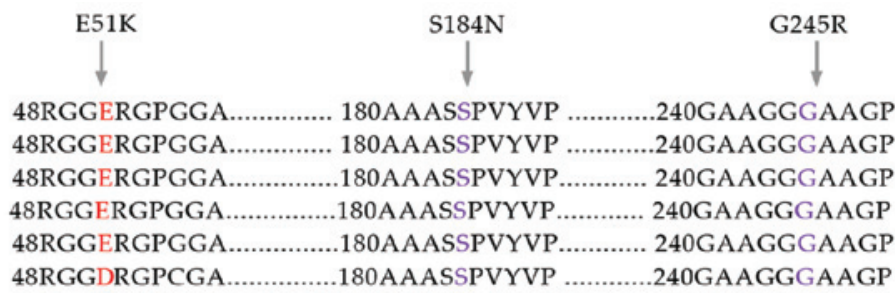

Figure 3. Multiple alignment of the sequences of the GATA6 protein from various species, indicating that the three heterozygous missense mutations are located at conserved sites. Arrow indicates the location of the mutations in conserved residues. GATA6, GATA binding protein 6.

continuous variables and $\mathrm{P}<0.05$ was considered to indicate a statistically significant difference.

\section{Results}

GATA6 mutations in patients with nonsyndromic CTD. Three heterozygous missense mutations (E51K, S184N and G245R) were identified in the GATA6 gene in 3/157 unrelated cases of nonsyndromic CTD. These sequence variants, which are located in coding exons and generate the amino acid alterations of E51K, S184N and G245R, were absent in the chromosomes of all healthy controls (Fig. 1). Overall, the mutation frequency of the GATA6 gene in nonsyndromic CTD was $1.9 \%(3 / 157)$. To the best of our knowledge, the current study is the first to report the $\mathrm{E} 51 \mathrm{~K}$ and $\mathrm{G} 245 \mathrm{R}$ heterozygous missense mutations. The c. $151 \mathrm{G}>\mathrm{A}$ in exon 2 , identified in a patient with TOF, changes a relatively conserved glutamic acid residue to lysine at position $51(\mathrm{E} 51 \mathrm{~K})$. This change was expected to have a significant impact on the structure and function of the GATA6 protein since glutamic acid is acidic, while lysine is basic. The 
Table II. Identification of GATA6 sequence variants in nonsyndromic CTD.

\begin{tabular}{|c|c|c|c|c|c|}
\hline \multirow[b]{2}{*}{ Location } & \multirow[b]{2}{*}{ Nucleotide change } & \multirow[b]{2}{*}{ dbSNP database } & \multirow[b]{2}{*}{ Amino acid change } & \multicolumn{2}{|c|}{ Allele frequency } \\
\hline & & & & Patients & Controls \\
\hline Exon 2 & c. $43 \mathrm{G}>\mathrm{C}$ & rs 116262672 & Gly15Arg & $\begin{array}{c}8 / 157 \\
(0.051)^{\mathrm{a}}\end{array}$ & $\begin{array}{l}21 / 300 \\
(0.070)\end{array}$ \\
\hline Exon 2 & c. $151 \mathrm{G}>\mathrm{A}$ & & Glu51Lys & $\begin{array}{c}1 / 157 \\
(0.006)^{\mathrm{b}}\end{array}$ & $\begin{array}{c}0 / 300 \\
(0.000)\end{array}$ \\
\hline Exon 2 & c. $.551 \mathrm{G}>\mathrm{A}$ & & Ser184Asn & $\begin{array}{c}1 / 157 \\
(0.006)^{\mathrm{b}}\end{array}$ & $\begin{array}{c}0 / 300 \\
(0.000)\end{array}$ \\
\hline Exon 2 & c. $733 \mathrm{G}>\mathrm{C}$ & & Gly245Arg & $\begin{array}{c}1 / 157 \\
(0.006)^{\mathrm{b}}\end{array}$ & $\begin{array}{c}0 / 300 \\
(0.000)\end{array}$ \\
\hline Intron 2 & c. $5825+19 \mathrm{C}>\mathrm{G}$ & rs76308670 & & $\begin{array}{c}1 / 157 \\
(0.006)^{\mathrm{a}}\end{array}$ & $\begin{array}{c}2 / 300 \\
(0.007)\end{array}$ \\
\hline Intron 2 & c. $10501-60 \mathrm{C}>\mathrm{T}$ & rs3764504 & & $\begin{array}{c}4 / 156 \\
(0.026)^{\mathrm{a}}\end{array}$ & $\begin{array}{c}8 / 300 \\
(0.027)\end{array}$ \\
\hline Intron 2 & c. $10501-85 \mathrm{~T}>\mathrm{C}$ & & & $\begin{array}{c}1 / 157 \\
(0.006)^{\mathrm{a}}\end{array}$ & $\begin{array}{c}2 / 300 \\
(0.006)\end{array}$ \\
\hline Intron 6 & c. $16589+6 \mathrm{~T}>\mathrm{C}$ & & & $\begin{array}{c}1 / 157 \\
(0.003)^{\mathrm{a}}\end{array}$ & $\begin{array}{c}2 / 300 \\
(0.007)\end{array}$ \\
\hline Intron 6 & c. $16589+7 A>G$ & rs3764962 & & $\begin{array}{c}9 / 157 \\
(0.057)^{\mathrm{a}}\end{array}$ & $\begin{array}{l}22 / 300 \\
(0.073)\end{array}$ \\
\hline 3'-UTR & c. $+72 \mathrm{G}>\mathrm{A}$ & rs1941084 & & $\begin{array}{c}67 / 157 \\
(0.427)^{\mathrm{a}}\end{array}$ & $\begin{array}{c}156 / 300 \\
(0.520)\end{array}$ \\
\hline 3'-UTR & c. $+77 \mathrm{G}>\mathrm{A}$ & rs1941083 & & $\begin{array}{c}26 / 157 \\
(0.166)^{\mathrm{a}}\end{array}$ & $\begin{array}{l}56 / 300 \\
(0.187)\end{array}$ \\
\hline
\end{tabular}

${ }^{\mathrm{a}} \mathrm{P}>0.05 ;{ }^{\mathrm{b}} \mathrm{P}<0.05$ compared with the control group. GATA6, GATA binding protein 6 ; CTD, conotruncal defect.

c. $733 \mathrm{G}>\mathrm{C}$ missense mutation in exon 2 , identified in a patient with PTA, leads to the substitution of a highly conserved glycine residue with arginine at position 245 (G245R). This mutation may also have a significant impact on the structure of a salt bond and thus the structure of the GATA6 protein since glycine is a non-polar hydrophobic amino acid, while arginine is basic. In addition, the c.551G $>\mathrm{A}$ missense mutation in exon 2 was identified in a patient with TOF, and substitutes a serine with an asparagine at position 184 (S184N). However, this mutation has been reported previously (13). As the two novel mutations are likely to alter the structure of the GATA6 protein, they may be pathogenic. The location and sequence alignment data for these mutations are shown in Figs. 2 and 3. Nonsyndromic CTD pathogenesis is not only related with the 22q11.2 microdeletion and $T B X 1$ gene mutations, but may also be involved in pathogenesis mediated by the GATA6 zinc-finger transcription factor.

Seven sequence variants were identified in introns and the 3'-UTR of GATA6 in patients with nonsyndromic CTD and control subjects. A previously reported sequence variant in exon 2 (c.43G>C) predicted to lead to an amino acid change (p.Gly15Arg) was also identified in the present study. This nucleotide substitution was identified in $8 / 157$ nonsyndromic CTD patients $(5.1 \%)$ and in $21 / 300$ control subjects $(7.0 \%)$ $(\mathrm{P}>0.05)$. Six of these sequence variants were already present in the dbSNP database (http://www.ncbi.nlm.nih.gov/SNP/). The other two intron sequence variants (c.10501-85T $>C$, intron 2; c.16589+6T >C, intron 6) were novel single nucleotide polymorphisms, but displayed no significant difference in their allele frequencies between patients with nonsyndromic CTD and control subjects. All sequence variants and their allele frequencies are summarized in Table II.

Characteristics and mutation screening of family members. The c.151G $>$ A proband was a male with TOF, and family members included two parents and siblings. A young brother of the proband was confirmed to be suffering from trisomy 21 associated with an atrioventricular septal defect (AVSD), but his parents and sister had normal cardiac morphology. The c. $151 \mathrm{G}>\mathrm{A}$ missense mutation was identified in his father and brother. The c.551G $>\mathrm{A}$ and the c.733G $>\mathrm{C}$ probands were males with TOF and PTA, respectively, and family members included parents but no siblings in both cases. These parents all had normal cardiac morphology and there were no GATA6 sequence variants identified (Fig. 4).

E51K and G245R cause a significant reduction in the capacity of GATA6 to transactivate downstream genes. Among the three mutations (E51K, S184N and G245R), S184N has been reported in a previous study by Lin et al (13). In the current study, the 

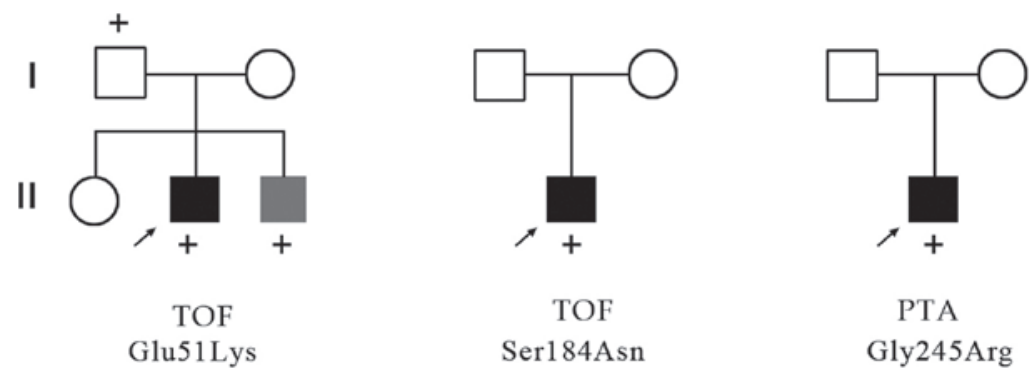

Figure 4. Characteristics and presence of mutations in the three families. Arrow, proband; +, carriers of the mutations Glu51Lys, Ser184Asn and Gly245Arg; black box, nonsyndromic conotruncal heart defects patient; grey box, trisomy 21 patient; TOF, tetralogy of Fallot, PTA, persistent truncus arteriosus.

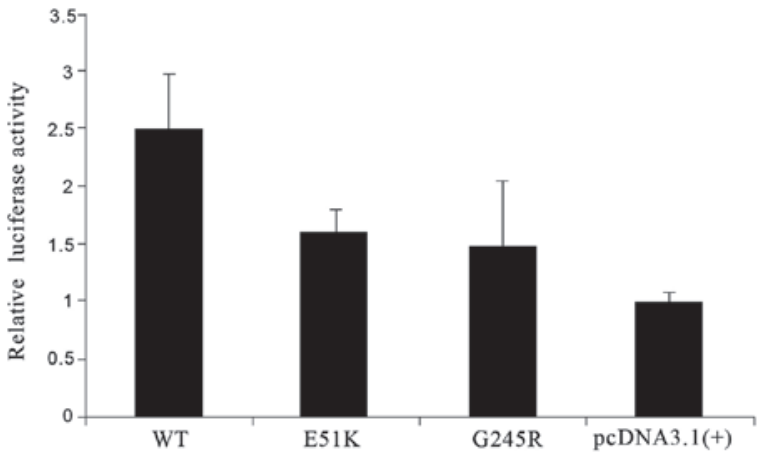

Figure 5. The transactivation function of mutant GATA6 was disrupted. The data are expressed as the mean \pm standard deviation of two independent experiments performed in triplicate, and the relative luciferase value of control, pcDNA3.1 (+) was set at 1. WT, wild type; GATA6, GATA binding protein 6.

transcription capacities of the E51K and G245R proteins in cultured cells were determined. The ANF-luciferase construct in which the reporter gene expression was driven by the ANF promoter was co-transfected into HEK293T cells with wild-type or mutant GATA6. The expressed GATA6 molecules bound to the ANF sequence and then transactivated luciferase expression downstream. The luciferase activity normalized to the $L a c Z$ value was regarded as the relative transactivation function of GATA6. E51K diminished the transactivation activity by almost $40 \%$ and G245R interrupted it more markedly (>40\%) compared with that of wild-type GATA6 (Fig. 5).

\section{Discussion}

GATA6 is an early marker of cardiac precursor cells, an important transcription factor for cardiac cell differentiation and development, and one of the major candidate genes in the pathogenesis of congenital heart diseases, particularly conotruncal heart defects $(10,14)$. The human GATA6 gene is localized to chromosome 18q11.1-11.2, contains seven exons spanning 34,812 bp and encodes a protein comprising 595 amino acids (15). GATA6 expression in the cardiac neural crest during embryonic development can be visualized with FISH, and data obtained using this technique supports the hypothesis that GATA6 not only regulates differentiation of smooth muscle cells in the cardiac neural crest but also regulates development of the aorticopulmonary septum through signaling from cells derived from the neural crest $(9,16)$. In the wild-type embryonic heart, GATA6 mRNA is expressed in the cardiac outflow tract, atrium and ventricles 9.5 days post-conception. GATA6 is expressed in the ascending aorta, pulmonary artery smooth muscle cells, and the endocardial cushion that differentiates into the cardiac outflow tract conotruncus 11.5 days post-conception. Furthermore, GATA6 mRNA detected at 12.5 days post-conception is localized in the aorta, pulmonary artery, VSMCs of the ductus arteriosus, cardiomyocytes of the atrium and ventricles, and the endocardial cushion of the conotruncus $(17,18)$. It is reported that of the GATA gene family, only GATA6 is expressed in VSMCs and it mediates their differentiation through modulating the expression of VSMC-specific genes, including $\alpha$-MHC, $\alpha$-actin and $S M 22$, in order to maintain various differentiated vascular smooth muscle phenotypes (19-23).

Three GATA6 missense mutations that were demonstrated to be associated with single conotruncal heart defects were identified in the current study, and two of these were novel (E51K and G245R). The E51K mutation was not demonstrated to be located in the transcriptional activation, zinc finger or nuclear localization signaling domains; however, this mutation results in the replacement of an acidic with a basic amino acid at position 51. Furthermore, the region of the GATA6 sequence containing this mutation is important in the transactivation of target genes. It is therefore reasonable to suggest that the E51K mutation significantly affects the structure, stability, and hence, the transcriptional activity of the GATA6 protein. It was also indicated that the $\mathrm{G} 245 \mathrm{R}$ mutation results in changes to salt bonds and may alter the structure of the GATA6 protein.

These assumptions were confirmed by functional analysis in the present study. The E51K and G245R mutations reduced the capacity of GATA6 to transactivate downstream genes by $\sim 40 \%$ compared with that of wild-type GATA6. Lin et al (13) previously identified S184N missense mutations in one patient with TOF and one with an atrial septal defect, and then demonstrated that the mutation led to reduced transcriptional activity of GATA6 (13). The mutant GATA6 appears to attenuate the expression of certain downstream genes which modulate the formation of the cardiac outflow tract, endocardial cushion and the atrioventricular septa, and this may be the genetic mechanism underlying nonsyndromic CTDs.

Thus far, studies have reported GATA6 mutations in congenital heart disease. Kodo et al (10) reported the $\mathrm{N} 466 \mathrm{H}$ mutation in the zinc finger domain and the E486del mutation in the nuclear localization signaling domain in patients with PTA. They also demonstrated that the mutant proteins did not 
transactivate target genes, thus disrupting normal regulation of the semaphorin-plexin signaling pathway and resulting in cardiac outflow tract malformations. Maitra et al (24) identified two missense mutations of the GATA6 gene in one patient with TOF (A178V) and one with AVSD (L198V). They also demonstrated that the A178V mutation leads to increased GATA6 transcriptional activity. In the present study, a detailed phenotype and genotype characterization of the family members of all patients with GATA6 mutations was performed. The results displayed that the father and brother of the proband with the E51K mutation also had the mutation $(\mathrm{c} .151 \mathrm{G}>\mathrm{A})$; however, the father had normal cardiac morphology, suggesting incomplete penetrance of this mutation. The brother was diagnosed with trisomy 21 syndrome with AVSD. It is reported that $40-60 \%$ of patients with trisomy 21 syndrome exhibit some form of congenital heart disease; however, trisomy 21 alone is insufficient to cause congenital heart disease as $\sim 50 \%$ of patients with trisomy 21 have a normal heart $(25,26)$. It has been suggested that the etiology for heart defects in trisomy 21 with AVSD involves mutations in the CRELD1, HEY2 and ALK2 genes (26-28). The present study suggests that mutation of the GATA6 gene may also be involved in the pathogenesis of AVSD.

The results of the present study demonstrated that mutations of the GATA6 gene are closely related to nonsyndromic CTDs, suggesting an important role for this gene in the development of the human heart conotruncus. However, the development and differentiation of the human heart is a complex process and many factors contribute to the pathogenesis of abnormal heart structures, including genetic mutation, epigenetic modification and abnormal gene-environment interactions. Further studies are therefore required to clarify the role of the GATA6 mutations in the pathogenesis of heart malformations, particularly in CTD.

\section{Acknowledgements}

The authors thank all the patients and their families who participated in this study, Professor Hiroyuki Yamagishi and Professor Vidu Garg for kindly offering plasmids, and all the staff of the Children's Heart Center of Xinhua Hospital for their assistance. This study was supported by the ' 973 ' Program Fund of China (2010CB529501), the funding of Shanghai sample of clinical research center construction projects (08DZ2293105) and the Shanghai University Innovation Team.

\section{References}

1. Hoffman JI and Kaplan S: The incidence of congenital heart disease. J Am Coll Cardiol 39: 1890-1900, 2002.

2. Debrus S, Berger G, de Meeus A, et al: Familial non-syndromic conotruncal defects are not associated with a 22 q11 microdeletion. Hum Genet 97: 138-144, 1996.

3. Jenkins KJ, Correa A, Feinstein JA, et al; The American Heart Association Council on Cardiovascular Disease in the Young: Noninherited risk factors and congenital cardiovascular defects: current knowledge: a scientific statement from the American Heart Association Council on Cardiovascular Disease in the Young: endorsed by the American Academy of Pediatrics. Circulation 115: 2995-3014, 2007.

4. Cooper WO, Hernandez-Diaz S, Arbogast PG, et al: Major congenital malformations after first-trimester exposure to ACE inhibitors. N Engl J Med 354: 2443-2451, 2006.

5. Goldmuntz E, Clark BJ, Mitchell LE, et al: Frequency of 22 q11 deletions in patients with conotruncal defects. J Am Coll Cardiol 32: 492-498, 1998
6. Xu YJ, Wang J, Xu R, et al: Detecting 22q11.2 deletion in Chinese children with conotruncal heart defects and single nucleotide polymorphisms in the haploid TBX1 locus. BMC Med Genet 12: 169,2011

7. Morrisey EE, Tang Z, Sigrist K, et al: GATA6 regulates HNF4 and is required for differentiation of visceral endoderm in the mouse embryo. Genes Dev 12: 3579-3590, 1998.

8. Zhao R, Watt AJ, Battle MA, Li J, Bondow BJ and Duncan SA: Loss of both GATA4 and GATA6 blocks cardiac myocyte differentiation and results in acardia in mice. Dev Biol 317: 614-619, 2008.

9. Lepore JJ, Mericko PA, Cheng L, Lu MM, Morrisey EE and Parmacek MS: GATA-6 regulates semaphorin 3C and is required in cardiac neural crest for cardiovascular morphogenesis. J Clin Invest 116: 929-939, 2006.

10. Kodo K, Nishizawa T, Furutani M, et al: GATA6 mutations cause human cardiac outflow tract defects by disrupting semaphorin-plexin signaling. Proc Natl Acad Sci USA 106: 13933-13938, 2009.

11. Sprenkle AB, Murray SF and Glembotski CC: Involvement of multiple cis elements in basal- and alpha-adrenergic agonist-inducible atrial natriuretic factor transcription. Roles for serum response elements and an SP-1-like element. Circ Res 77: 1060-1069, 1995

12. Bamforth SD, Bragança J, Eloranta JJ, et al: Cardiac malformations, adrenal agenesis, neural crest defects and exencephaly in mice lacking Cited2, a new Tfap2 co-activator. Nat Genet 29: 469-474, 2001.

13. Lin X, Huo Z, Liu X, et al: A novel GATA6 mutation in patients with tetralogy of Fallot or atrial septal defect. J Hum Genet 55: 662-667, 2010.

14. Burch JB: Regulation of GATA gene expression during vertebrate development. Semin Cell Dev Biol 16: 71-81, 2005.

15. Brewer A and Pizzey J: GATA factors in vertebrate heart development and disease. Expert Rev Mol Med 8: 1-20, 2006.

16. Barillot W, Tréguer K, Faucheux C, Fédou S, Thézé N and Thiébaud P: Induction and modulation of smooth muscle differentiation in Xenopus embryonic cells. Dev Dyn 237: 3373-3386, 2008.

17. Stoller JZ and Epstein JA: Cardiac neural crest. Semin Cell Dev Biol 16: 704-715, 2005.

18. Brown CB, Feiner L, Lu MM, et al: PlexinA2 and semaphorin signaling during cardiac neural crest development. Development 128: 3071-3080, 2001

19. Yang H, Lu MM, Zhang L, Whitsett JA and Morrisey EE: GATA6 regulates differentiation of distal lung epithelium. Development 129: 2233-2246, 2002

20. Fischer A, Klattig J, Kneitz B, et al: Hey basic helix-loop-helix transcription factors are repressors of GATA4 and GATA6 and restrict expression of the GATA target gene ANF in fetal hearts. Mol Cell Biol 25: 8960-8970, 2005.

21. Suzuki E, Evans T, Lowry J, Truong L, Bell DW, Testa JR and Walsh K: The human GATA-6 gene: structure, chromosomal location, and regulation of expression by tissue-specific and mitogen-responsive signals. Genomics 38: 283-290, 1996.

22. Mano T, Luo Z, Malendowicz SL, Evans T and Walsh K: Reversal of GATA-6 downregulation promotes smooth muscle differentiation and inhibits intimal hyperplasia in balloon-injured rat carotid artery. Circ Res 84: 647-654, 1999.

23. Morrisey EE: GATA-6: the proliferation stops here: cell proliferation in glomerular mesangial and vascular smooth muscle cells. Circ Res 87: 638-640, 2000.

24. Maitra M, Koenig SN, Srivastava D and Garg V: Identification of GATA6 sequence variants in patients with congenital heart defects. Pediatr Res 68: 281-285, 2010.

25. Loffredo CA, Hirata J, Wilson PD, Ferencz C and Lurie IW: Atrioventricular septal defects: possible etiologic differences between complete and partial defects. Teratology 63: 87-93, 2001.

26. Li H, Cherry S, Klinedinst D, et al: Genetic modifiers predisposing to congenital heart disease in the sensitized Down syndrome population. Circ Cardiovasc Genet 5: 301-308, 2012.

27. Guo Y, Shen J, Yuan L, Li F, Wang J and Sun K: Novel CRELD1 gene mutations in patients with atrioventricular septal defect. World J Pediatr 6: 348-352, 2010.

28. Joziasse IC, Smith KA, Chocron S, et al: ALK2 mutation in a patient with Down's syndrome and a congenital heart defect. Eur J Hum Genet 19: 389-393, 2011. 